\title{
Implementasi Forward Chaining Dan Breadth First Pada Sistem Pakar Diagnosa Gangguan Kehamilan
}

\author{
Sri Handani Widiastuti ${ }^{1}$, Nur Imansyah ${ }^{2}$ \\ ${ }^{1,2}$ Sekolah Tinggi Teknologi Bontang \\ Jl. Letjen S. Parman No. 65, 75313 Indonesia \\ ${ }^{1}$ handaniwidiastuti@yahoo.com, 2n_imansyah@yahoo.com
}

\begin{abstract}
Expert system is a computer-based system that uses knowledge, facts and reasoning techniques in solving problems that can usually only be solved by an expert. Inference method is a thinking mechanism and reasoning patterns used by the system to reach conclusions, while forward chaining is an inference method that traces starting from a set of facts by looking for rules that match the guesswork / hypothesis that leads to conclusions. Expert systems can be applied in various fields, including in medicine, for example how to diagnose a disease. Pregnancy is a happy moment for a mother, but there are still many problems with pregnancy problems in pregnant women because many do not know about pregnancy disorders that usually occur. Puskesmas Bontang Utara I has a program to reduce mortality in pregnant women and infants, by providing guidance and socialization on how to maintain a correct pregnancy. To facilitate public understanding and provide information related to pregnancy disorders, the researchers made the application system expert pregnancy disorders built using the PHP programming language, Dreamweaver 8 as an editor and MySql as the database. Software development methods use the waterfall model and system testing using blackbox. The expert system application in this study provides information on diagnosing pregnancy disorders in pregnant women such as consulting with experts. The diagnostic process starts with the way the user selects or inputs the type of complaint that is felt in accordance with the symptoms provided by the system. By using the forward chaining method and breadth first search search technique, the complaints that have been entered will be matched with the symptoms and types of disturbances stored in the database. So that the results of the diagnosis will be produced as the results of the diagnosis of experts. With this information helps pregnant women recognize pregnancy disorders during pregnancy.
\end{abstract}

Abstrak - Sistem pakar adalah sistem berbasis komputer yang menggunakan pengetahuan, fakta, dan teknik penalaran dalam memecahkan masalah yang biasanya hanya dapat dipecahkan oleh seorang pakar. Metode inferensi merupakan mekanisme berfikir dan pola-pola penalaran yang digunakan oleh sistem untuk mencapai kesimpulan, sedangkan forward chaining adalah metode inferensi yang melakukan pelacakan mulai dari sekumpulan fakta-fakta dengan mencari kaidah yang cocok dengan dugaan/hipotesa yang ada menuju kesimpulan. Sistem pakar dapat diterapkan diberbagai bidang, termasuk dibidang kedokteran misalnya cara mendiagnosa suatu penyakit. Kehamilan adalah moment membahagiakan bagi seorang ibu, tetapi masih banyak terdapat permasalahan gangguan kehamilan pada ibu hamil disebabkan banyak yang tidak tahu tentang gangguan kehamilan yang biasanya terjadi. Puskesmas Bontang Utara I mempunyai program memperkecil angka kematian pada ibu hamil dan bayi, dengan memberikan pengarahan dan sosialisasi cara menjaga kehamilan yang benar. Untuk mempermudah pemahaman masyarakat dan memberikan informasi terkait gangguan kehamilan maka peneliti membuat aplikasi sistem pakar gangguan kehamilan dibangun menggunakan bahasa pemrograman PHP, Dreamweaver 8 sebagai editor dan MySql sebagai databasenya. Metode pengembangan perangkat lunak menggunakan model waterfall dan pengujian sistem menggunakan blackbox. Aplikasi sistem pakar pada penelitian ini memberikan informasi diagnosa gangguan kehamilan pada ibu hamil seperti berkonsultasi dengan pakarnya. Proses diagnosa dimulai dengan cara, user memilih atau menginputkan jenis keluhan yang dirasakan sesuai dengan gejala-gejala yang disediakan oleh sistem. Dengan menggunakan metode forward chaining dan teknik penelusuran breadth first search, keluhan yang telah diinputkan tersebut akan dicocokkan dengan gejala dan jenis gangguan yang tersimpan dalam database. Sehingga akan dihasilkan hasil diagnosa seperti hasil diagnosa pakarnya. Dengan adanya informasi tersebut membantu para ibu hamil mengenali gangguan- gangguan kehamilan pada masa kehamilan.

Keywords - Breadth first search, forward chaining, gangguan kehamilan, sistem pakar.

\section{Pendahuluan}

Sistem pakar adalah salah satu penerapan dari kecerdasan buatan tentang pengetahuan dan pengalaman yang dimasukan oleh satu atau banyak pakar ke dalam satu area pengetahuan tertentu sehingga setiap orang dapat menggunakannya untuk memperoleh informasi dalam memecahkan masalah. Atau dapat juga diartikan bahwa sistem pakar adalah sistem yang berusaha mengadopsi pengetahuan manusia ke komputer, agar komputer dapat menyelesaikan masalah layaknya seperti para pakar. Kehamilan adalah merupakan suatu kondisi seorang wanita memiliki janin yang tengah tumbuh dalam tubuhnya. Salah satu masalah yang sering dihadapi oleh ibu hamil pada masa kehamilan adalah kurangnya informasi mengenai kesehatan pada ibu hamil [3]. Kurangnya informasi tentang pentingnya pelayanan kehamilan dan persalinan serta pelayanan antenatal, maka sedikit pula informasi tentang gangguan kehamilan yang didapat. Gangguan kehamilan dapat terjadi pada periode kehamilan 
seseorang yaitu pada tri semester pertama, kedua atau ketiga. Apilkasi sistem pakar yang akan dirangcang ini bertujuan untuk memberikan informasi seperti pelayanan kehamilan, persalinan dan antenatal pada ibu hamil untuk mendiagnosa gangguan kehamilan yang dialami oleh ibu hamil. Jenis dan ragam gangguan kehamilan perlu diketahui agar ibu hamil cepat bertindak dan meminimalisasi resiko kehamilan ataupun persalinan. Pelayanan obstetric yang masih terbatas menjadi salah satu factor penyebab tingginya angka kematian ibu hamil [5]. Puskesmas Bontang Utara I mempunyai program memperkecil angka kematian pada ibu hamil dan bayi, dengan meningkatkan pelayanan obstetri yaitu pelayanan kesehatan yang memberikan pengetahuan, pengarahan dan sosialisasi cara menjaga kehamilan yang benar serta pemeriksaan mengenai kehamilan dan gangguang kehamilan yang disampaikan oleh dokter sesuai bidangnya. Untuk mempermudah pemahaman masyarakat dan memberikan informasi terkait gangguan kehamilan maka peneliti membuat aplikasi sistem pakar atau sistem yang memiliki pengetahuan seperti seorang pakar dalam mecari solusi. Sehingga dapat membantu mendiagnosa gangguan kehamilan bedasarkan gejala atau keluhan yang dirasakan.

Metode forward chaining digunakan mediagnosa gangguan kehamilan seperti Kehamilan Ektopik, Hidramnion, Toksoplasmosis, Korioamnionitis, Blighted Ovum, Mola Hidatidosa, Plasenta Previa, Solusio Plasenta dan Abortus Insipiens.

\section{Metode Penelitian}

Tahap-tahap yang digunakan dalam mengembangkan sistem menggunakan metodologi waterfall[7], gambaran bagan metode waterfall terdapat pada gambar 1

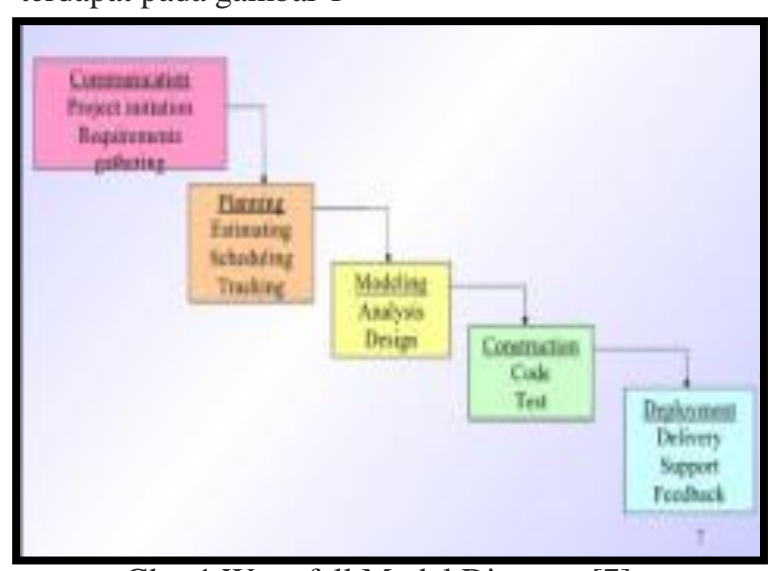

Gbr. 1 Waterfall Model Diagram [7]

Adapun tahap-tahapan model waterfall pada penelitian ini adalah sebagai berikut :

\section{A. Communication (Project Initiation \& Requirements Gathering)}

Komunikasi untuk mencapai tujuan yang ingin dicapai, seperti menganalisis permasalahan yang dihadapi dan mengumpulkan data-data yang diperlukan.

\section{B. Planning}

Merupakan tahapan perencanaan yang menjelaskan tentang estimasi tugas-tugas teknis yang akan dilakukan, resiko-resiko yang dapat terjadi, sumber daya yang diperlukan dalam membuat system dan penjadwalan kerja yang akan dilaksanakan.

\section{Modeling (Analysis \& Design)}

Tahap ini merupakan tahap perancangan struktur data, arsitektur software, tampilan interface dan algoritma program. Hal ini bertujuan untuk lebih memahami gambaran besar dari apa yang akan dikerjakan. Gambaran alur sistem manual diagnosa gangguan kehamilan terdapat pada gambar 2 .

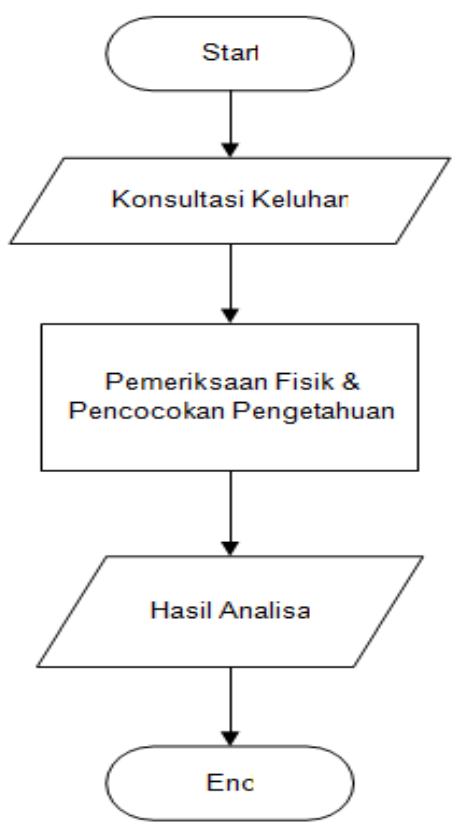

Gbr. 2 Flowchart system manual diagnosa gangguan kehamilan

Sedangkan gambaran alur sistem pakar diagnosa gangguan kehamilan terdapat pada gambar 3 . 


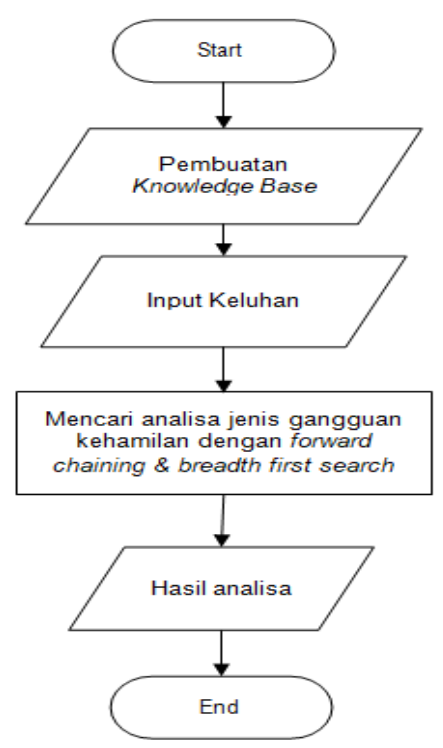

Gbr. 3 Flowchart sistem pakar diagnosa gangguan kehamilan

Aplikasi system pakar gangguan kehamilan yang dirancang adalah menggunakan metode forward chaining dan breath first search (BFS) dalam proses pencocokan gejala dan hasil diagnosa. Gambaran rancangan sistem pakar diagnosa gangguan kehamilan terdapat pada gambar 4 dan gambar 5 .

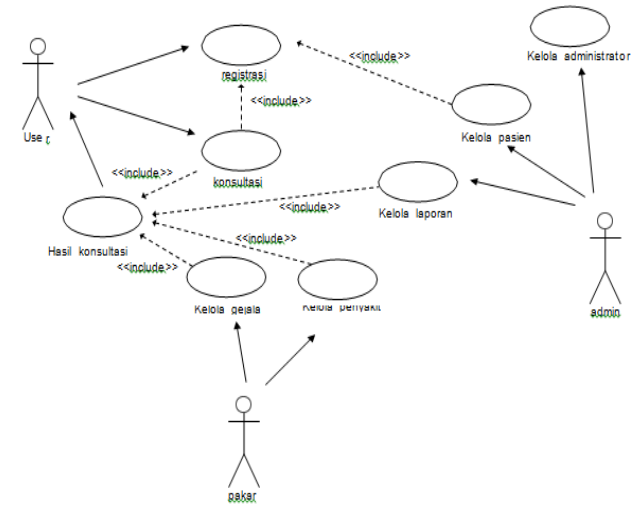

Gbr. 4 Use case diagram sistem pakar dengan metode forward chaining dan BFS

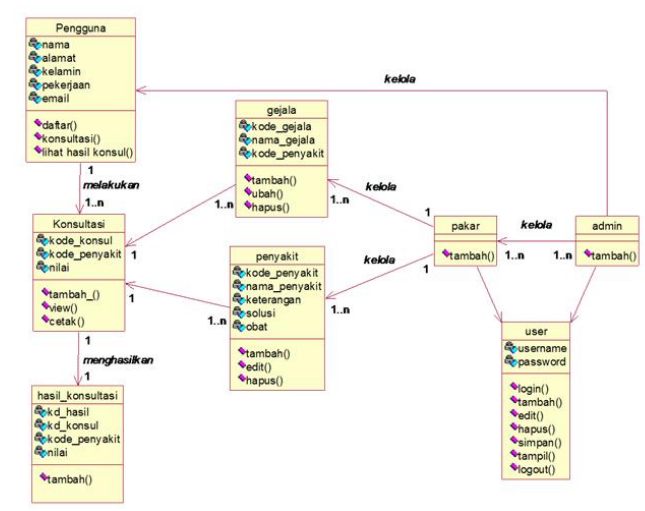

Gbr. 5 Class diagram sistem pakar dengan metode forward chaining dan BFS

\section{Construction (Code \& Test)}

Tahapan construction ini merupakan proses pembuatan program aplikasi sistem pakar, kemudian diimplementasikan. Selanjutnya pengujian program aplikasi yang dibuat dengan menggunakan metode blackbox atau whitebox. Hal ini bertujuan untuk menemukan kesalahan atau kekurangan yang mungkin terjadi untuk diperbaiki. Contoh gambaran antarmuka aplikasi sistem pakar gangguan kehamilan yang sudah dibuat dapat dilihat pada gambar 6, gambar 7, gambar 8 dan gambar 9.

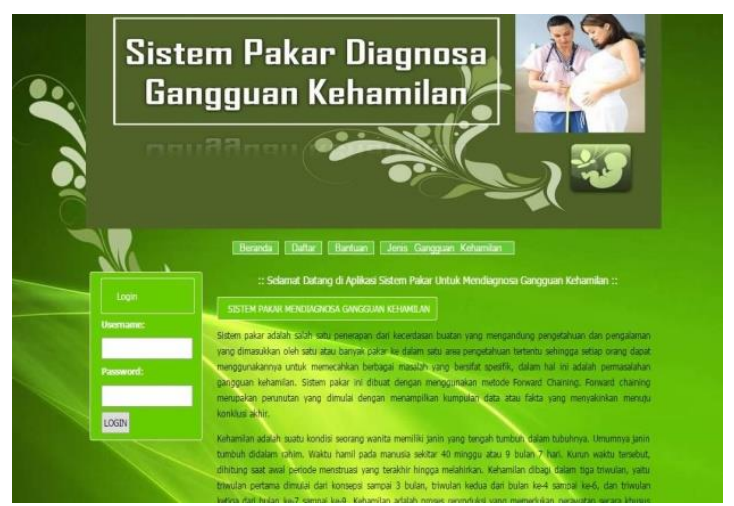

Gbr. 6 Halaman utama aplikasi system pakar diagnosa gangguan kehamilan

Gambar 6 adalah tampilan halaman utama pada aplikasi sistem pakar diagnose gangguan kehamilan dengan metode forward chaining dan BFS.

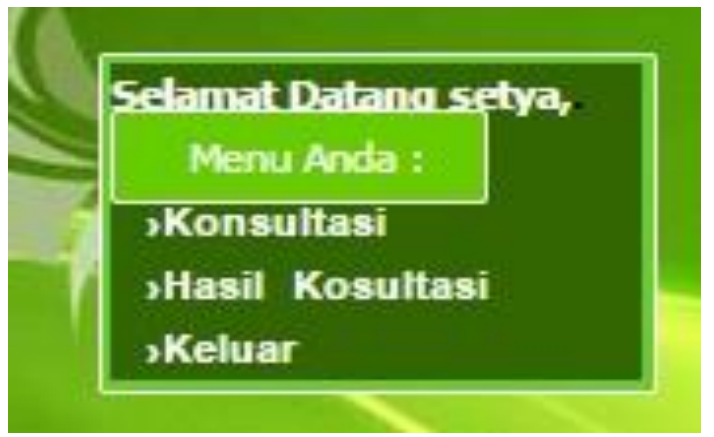

Gbr. 7 Halaman menu konsultasi aplikasi system pakar diagnosa gangguan kehamilan

Gambar 7 adalah tampilan halaman menu bagi user setelah login, pada halaman ini terdapat menu pilihan konsultasi, hasil konsultasi dan keluar.

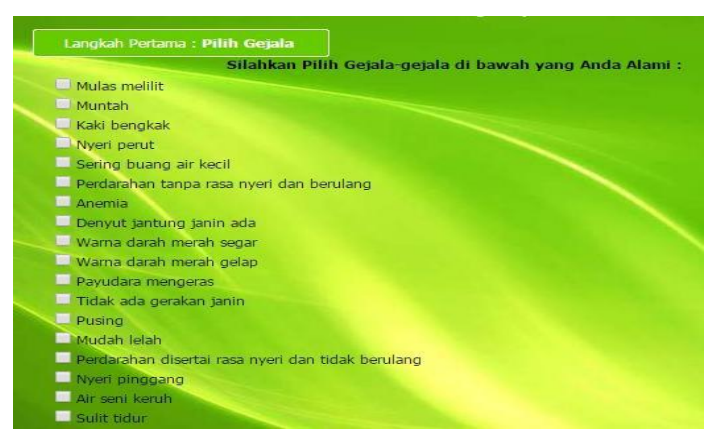

Gbr. 8 Halaman pilih gejala aplikasi system pakar diagnosa gangguan kehamilan 
Pada saat user memilih/mengklik menu konsultasi maka akan masuk ke halaman pilih gejala seperti yang terlihat pada gambar 8. Pada halaman ini user tinggal memilih gejala-gejala yang dialami.

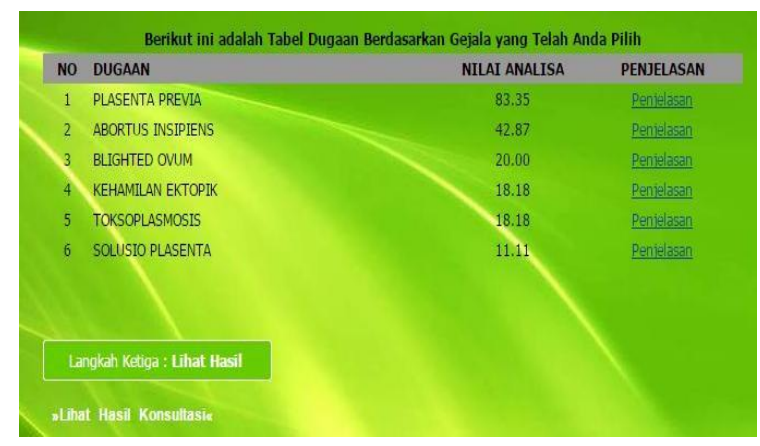

Gbr. 9 Halaman hasil diagnosa aplikasi sistem pakar diagnose gangguan kehamilan

Selanjutnya setelah mengklik tombol hasil maka akan masuk ke halaman hasil diagnose seperti yang terdapat pada gambar 9 .

\section{E. Deployment (Delivery, Support, Feedback)}

Pada tahap ini dilakukan implementasi software ke customer, pemeliharaan software, evaluasi software dan pengembangan software. Cara paling mudah untuk memenuhi persyaratan format penulisan adalah dengan menggunakan dokumen ini sebagai template. Kemudian ketikkan teks anda ke dalamnya

\section{HASIL DAN DISKUSI}

Dalam pencarian diagnosa gangguan kehamilan pada penelitian ini, melalui beberapa tahap yaitu ;

1. Menyusun knowledge base dengan cara ;

a. Membuat tabel pada database yang berisi gejala-gejala yang didapat dari pakar.

b. Selanjutnya memberikan kode jenis gangguan kehamilan sesuai dengan data gejala yang telah dibuat. Seperti yang terlihat pada gambar 10 .

2. Menginputkan gejala/keluhan gangguan kehamilan, misalnya mulas melilit, perdarahan tanpa rasa nyeri berulang, anemia, lemah lesu, warna darah merah segar, sulit tidur, dan mudah lelah (ada 6 gejala).

3. Gejala tersebut akan dicocokkan dengan gejala dan jenis gangguan kehamilan yang tersimpan di dalam database dengan metode forward chaining dan penelusuran breadth first search, seperti yang terdapat pada gambar 11 .

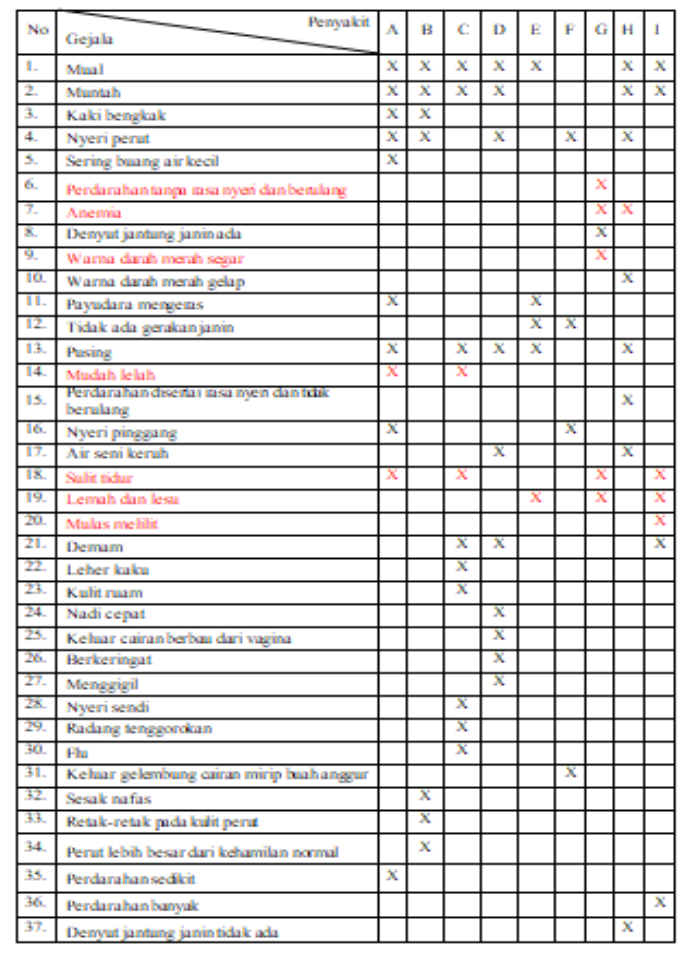

Gbr 10 Tabel knowledge base

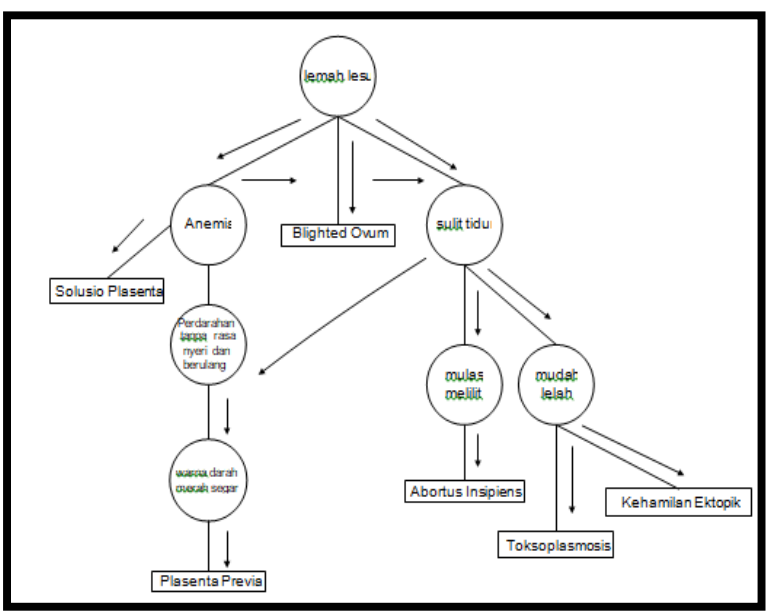

Gbr 11 Penelusuran Breadth First Search

4. Setelah semua gejala cocok, sistem akan mengelompokkan jumlah gejala terpilih dengan jenis gangguan kehamilan menggunakan rule/aturan pada metode forward chaining .

a. IF mulas melilit AND lemah lesu AND sulit tidur THEN abortus insipiens.

b. IF sulit tidur AND mudah lelah THEN kehamilan ektopik, toksoplasmosis.

c. IF lemah lesu THEN blighted ovum.

d. IF anemia THEN solusio plasenta.

e. IF anemia AND lemah lesu AND sulit tidur AND perdarahan tanpa rasa nyeri berulang AND warna darah merah segar THEN plasenta previa. 
5. Setelah pengelompokan gejala dan jenis gangguan kehamilan selesai, kemudian sistem akan menghitung dengan cara, jumlah gejala terpilih dibagi jumlah keseluruhan dari setiap jenis gangguan kehamilan.

a. Diagnosa Plasenta Previa dengan gejala perdarahan tanpa rasa nyeri dan berulang, anemia, warna darah merah segar, sulit tidur, lemah lesu.

b. Diagnosa Arbotus Insipiens dengan gejala Lemah lesu, mulas melilit, sulit tidur.

c. Diagnosa Blighted Ovum dengan gejala yang sama lemah lesu.

d. Diagnosa Toksoplasmosis dengan gejala yang sama sulit tidur, mudah lelah

e. Diagnosa Kehamilan Ektopik dengan gejala yang sama sulit tidur, mudah lelah.

f. Diagnosa Solusio Plasenta dengan gejala yang sama anemia.

Dari data tersebut diatas diperoleh daftar banyaknya gejala yang diinputkan dengan gejala pada knowledge base yaitu ;

a. Jumlah gejala yang cocok pada plasenta previa $=5$ gejala

b. Jumlah gejala yang cocok pada Arbotus Insipiens $=3$ gejala

c. Jumlah gejala cocok pada pada Toksoplasmosis $=2$ gejala

d. Jumlah gejala yang cocok pada Kehamilan Ektopik $=2$ gejala

e. Jumlah gejala uang cocok pada Blighted Ovum = 1 gejala

f. Jumlah gejala yang cocok pada Solusio Plasenta $=1$ gejala

6. Menghitung rasio gejala yang diinputkan dengan gejala yang sesuai dengan pencocokan/ bernilai benar menggunakan persamaan ;

$$
\text { Rasio }=\frac{a}{b} x 100 \%
$$

Rasio Plasenta Previa $=\frac{\mathbf{5}}{\mathbf{6}} \times 100 \%=83,35 \%$

Rasio Arbotus Insipiens $=\frac{3}{6} \times 100 \%=50 \%$

Rasio Toksoplasmosis $=\frac{2}{6} \times 100 \%=33,33 \%$

Rasio Kehamilan Ektopik $=\frac{2}{6} \times 100 \%=33,33 \%$

Rasio Blighted Ovum $=\frac{1}{6} \times 100 \%=16,67 \%$

Rasio Solusio Plasenta $=\frac{1}{6} \times 100 \%=16,67 \%$

7. Sistem akan menampilkan hasil diagnosa prosentase tertinggi berdasarkan gejala yang diinputkan, seperti yang terlihat pada gambar 12.

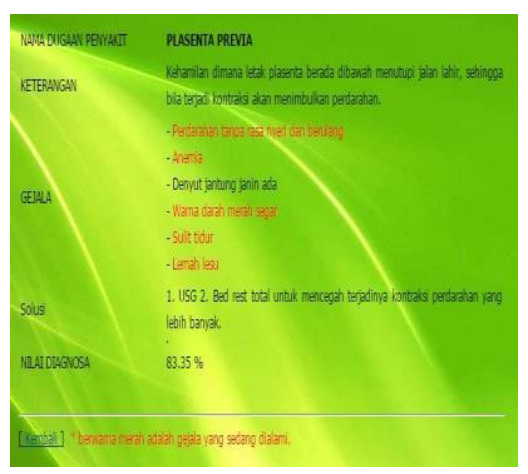

Gbr. 12 Hasil diagnosa berdasarkan rasio terbesar.

\section{Kesimpulan}

Dari penjelasan dan pembahasan hasil perancangan sistem pakar untuk mendiagnosa gangguan kehamilan dapat diambil kesimpulan sebagai berikut

1. Aplikasi sistem pakar ini bisa mengimplementasikan artificial intelligence dan menghasilkan informasi hasil analisa tentang gangguan kehamilan pada ibu hamil.

2. Memberikan kemudahan informasi dengan hasil diagnosa gangguan kehamilan seperti layaknya berkonsultasi dengan seorang pakar.

\section{Referensi}

[1] Abdillah A, Nurajijah N, Nawawi, "Perancangan Sistem Pakar Diagnosa Penyakit Kehamilan Berbasis Web", Jurnal Techno Nusa Mandiri, vol. 15, no. 2, pp. 115-120, 2018.

[2] Dwi Ratnasari D, Sutariyani, "Sistem Pakar Diagnosa Gangguan Kehamilan Dengan Metode Forward Chainging", Jurnal Ilmiah Go Infotech, vol. 21, no. 2, pp. 25-31, 2015

[3] Frieyadie, Aryanti H, "Sistem Pakar Diagnosa Gangguan Kehamilan Berbasis Web Dengan Menggunakan Metode Forward Chaining Pada RSIA RP Soeroso", Jurnal Pilar Nusa Mandiri, vol. IX, no. 1, pp. 62-68, 2013

[4] Hanifah Aji A, Tanzil Furqon M, Wahyu Widodo A, "Sistem Pakar Diagnosa Penyakit Ibu Hamil Menggunakan Metode Certainty Factor (CF)", Jurnal Pengembangangan Teknologi Informasi dan Ilmu Komputer, vol. 2, no. 5, pp. 2127-2134, 2018.

[5] Whenty H.B., Delima R., Purwadi J., "Program Bantu Diagnosa Gangguan Kesehatan Kehamilan dengan Metode Forward Chaining”, Jurnal Teknologi InformasiAiti, vol. 7, no. 1, pp. 1-19, 2010.

[6] Arhami M., Konsep Dasar Sistem Pakar. Yogyakarata : ANDI OFFSET, 2006.

[7] Roger S.Pressman, Bruce R. Maxim, Software Engineering: A Practitioner's Approach. English : McGraw-Hill Education; 8 edition, 2014. 